\title{
Inhibition of observing by a concurrent reinforcement schedule
}

\author{
DONALD M. WILKIE, THOMAS E. WHALEN, and DONALD G. RAMER \\ University of British Columbia, Vancouver, Canada V6T 1W5
}

\begin{abstract}
Pigeons were exposed to an observing-response procedure in which pecks on an observing key converted the prevailing mixed variable-interval extinction schedule of food reinforcement into the corresponding multiple schedule for a brief period of time. During some sessions, additional food reinforcement was concurrently presented. Introducing additional food reinforcement attenuated the rate of pecking the observing key. This result shows that the inhibiting effects of concurrent reinforcement are quite pervasive.
\end{abstract}

The rate at which a food-reinforced response is made in the presence of one stimulus is affected by reinforcement, but not responding, during concurrent stimuli. This effect was first shown by Catania (1963). In this experiment, pigeons' pecking one colored key was reinforced with food according to a variable-interval (VI) schedule. At times during the experiment, pecking a second colored key was reinforced with food according to an independent VI schedule. Introducing reinforcement for pecking the second key lowered the rate of pecking the first key. At other times. the availability of reinforcement for pecking the second key was signaled, thus reducing response rate on this key. Response rate on the first key was independent of amount of responding on the second key.

The inhibiting effects on responding by concurrent reinforcement do not appear to be limited to a reduction in the rate of a behavior maintained by a simple food reinforcement schedule. Catania and Dobson (1972), for example, found that accuracy on an oddity task was affected by concurrent reinforcement. In their experiment, pigeons' pecking the odd-colored key in a triangular array of three colored keys was reinforced with food according to a VI schedule. The rate of VI food reinforcement scheduled concurrently for pecks on a fourth, spatially isolated, differently colored key was varied. Both response rate and accuracy (percentage of pecks on the odd key) varied inversely with the rate of concurrent reinforcement.

This research was supported by National Research Council of Canada Grant No. A8353 to Donald M. Wilkie and a National Research Council of Canada postgraduate scholarship to Thomas E. Whalen. Thomas E. Whalen is now a graduate student in the Department of Psychology, Dalhousie University, Halifax, Nova Scotia. Canada. Reprints may be obtained from Donald M. Wilkie, Department of Psychology, University of British Columbia, Vancouver, British Columbia, Canada V6T 1W5.
Catania and Dobson's finding suggests that the effects of concurrent reinforcement may be quite general and that concurrent reinforcement may inhibit responding in a wide variety of situations. The results of another part of their experiment, however, show that concurrent reinforcement may sometimes facilitate, rather than inhibit, responding. In this stage, signaled VI reinforcement was available when the fourth key was one color but unavailable when this key was a different color. Under these conditions, oddity accuracy was higher when reinforcement was concurrently available. Thus, it appears that whether concurrent reinforcement has an inhibitory or facilitatory effect on other reinforced behavior may depend upon how such reinforcement is scheduled.

The present experiment further examined the generality of the effects of concurrent reinforcement upon reinforced responding by determining if the rate of an observing response is affected by concurrent reinforcement. In an observing response procedure, subjects are given the opportunity to emit a response that converts a mixed reinforcement schedule into the corresponding multiple schedule (Wyckoff, 1969). (When responding is reinforced according to two schedules that alternate in time, the procedure is called a mixed schedule if identical stimuli are associated with the component schedules, and a multiple schedule if different stimuli are associated with the component schedules.) Subjects emit these switching or observing responses under a number of conditions. Since such responses simply produce stimuli that are associated with reinforcement schedules, the occurrence of observing behavior must be accounted for in terms of properties of the schedule-correlated stimuli and not in terms of any gain in primary reinforcement.

Concurrent food reinforcement was arranged in two ways in different parts of the experiment. In both, the concurrent reinforcement was signaled. Reinforcement was contingent upon a keypeck in one but not the other part. 
Table 1

Number of Sessions Given Each Subject in Each Condition

\begin{tabular}{clrrr}
\hline $\begin{array}{c}\text { Condi- } \\
\text { tion }\end{array}$ & \multicolumn{1}{c}{$\begin{array}{c}\text { Concurrent } \\
\text { Reinforcement }\end{array}$} & S1 & $\begin{array}{c}\text { Subject } \\
\text { S2 }\end{array}$ & S3 \\
\hline 1 & Absent & 15 & 13 & 18 \\
2 & Response Dependent & 33 & 39 & 33 \\
3 & Absent & 14 & 11 & 11 \\
4 & Response Dependent & 10 & 10 & 17 \\
5 & Absent & 7 & 14 & 7 \\
6 & Response Dependent & 7 & 7 & 10 \\
7 & Absent & 15 & 17 & 12 \\
8 & Response Independent & 10 & 15 & 15 \\
9 & Absent & 14 & 12 & 10 \\
10 & Response Independent & 15 & 7 & 10 \\
\hline
\end{tabular}

\section{METHOD}

\section{Subjects}

Two King ( $S 2$ and S3) and one homing (S1) pigeon were maintained at approximately $85 \%$ of free-feeding weight for the duration of the experiment by mixed grain obtained during and immediately after experimental sessions. Water and health grit were continuously available in the home cage. Birds S2 and S3 had previously served in observing-response experiments (Spencer. Note 1): $S 1$ had served in a variety of experiments but had not been exposed to observing-response procedures prior to the present experiment

\section{Apparatus \\ The experimental chamber (LVE/BRS Model 1519) was constantly illuminated by a houselight and ventilated by a fan. The chamber itself. fan. and white noise attenuated extraneous sounds. A horizontal array of three response keys, a grain feeder, and a tone source were mounted on one wall. A projector was mounted directly behind each key and illuminated the keys with yellow, red. or green light. Automatic control of experimental sessions and data recording was arranged by solid state and electromechanical circuits.}

\section{Procedure}

With occasional exceptions. sessions were arranged for $1 \mathrm{~h}$ at approximately the same time each day, 7 days per week. The following procedures were arranged during each session. The center kev was normally illuminated with yellow light (the mixed stimulus). Pecking this key when it was yellow either produced $5.0 \mathrm{sec}$ access to grain according to a VI 1-min schedule, or was extinguished (EXT). The VI schedule consisted of a rectangular distribution of interreinforcement intervals ranging from 0 to $120 \mathrm{sec}$. The VI and EXT schedules alternated and were in effect for equal amounts of time during each session. The schedules alternated once every minute on the average. The times between alternations were $15,30,60,90$, and $105 \mathrm{sec}$, arranged in a mixed order.

The right (observing) key was also normally illuminated with vellow light. Pecking this key when it was yellow made it and the center foodkey green or red for $12 \mathrm{sec}$-green if the VI schedule was currently in effect and red if the EXT schedule was currently in effect. After $12 \mathrm{sec}$, both keys again became yellow. If the schedule of reinforcement changed during the 12 -sec period, the key color changed accordingly. A changeover delay (Catania, 1966) prevented pecks on the center foodkey from producing grain for $1.0 \mathrm{sec}$ after a peck on the observing key.

Each bird was exposed successively to 10 conditions. The number of sessions given each subject in each condition is shown in Table 1. Conditions were changed about every 10 days except when laboratory personnel work schedules, occasional apparatus failures, etc.. necessitated deviations. Conditions $1,3,5$, and 7 were identical to each other and to the procedures described above. During Conditions 2, 4, and 6 , the left key was illuminated with yellow light once every $2.0 \mathrm{~min}$ on the average. The illumination schedule consisted of a rectangular distribution of intervals ranging from 0 to $240 \mathrm{sec}$. A singie peck on the illuminated left key produced $5.0 \mathrm{sec}$ access to grain and turned off the yellow light after the expiry of a 1.0-sec changeover delay. Following a peck or reinforcement on the left foodkey, a changeover delay prevented reinforcement for pecks on the center foodkey for 1.0 sec.

Conditions 8 and 10 were identical. A tone was presented for $3.0 \mathrm{sec}$ once every $2.0 \mathrm{~min}$ on the average during these sessions. Offset of the tone was followed by $5.0 \mathrm{sec}$ access to grain. During Condition 9 sessions, the tone was presented for $3.0 \mathrm{sec}$ once every $2.0 \mathrm{~min}$ on the average but was not followed by food.

\section{RESULTS AND DISCUSSION}

Figure 1 shows the rate of pecking the observing key during the last five sessions of each of the 10 conditions. (Note that the maximum number of pecks on the observing key possible during the 1-h session is 300.) The rate of observing key responding generally was lower during conditions in which two sources of reinforcement were present. This decrease in pecking the observing key was independent of whether the additional reinforcement was arranged by the response-contingent (Conditions 2, 4, and 6) or response-independent (Conditions 8 and 10) schedule.

Table 2 shows the rate of center key responding in the presence of green, red, and yellow when concurrent reinforcement was absent and present. The rates shown are averages based on the last five sessions of Conditions 2, 4, 6, 8, and 10 and Conditions 1, 3, 5, 7, and 9, respectively. Responding during the mixed (yellow) stimulus was lower when concurrent reinforcement was present. Responding during the multiple schedule stimuli (green and red) was not systematically affected by concurrent reinforcement.

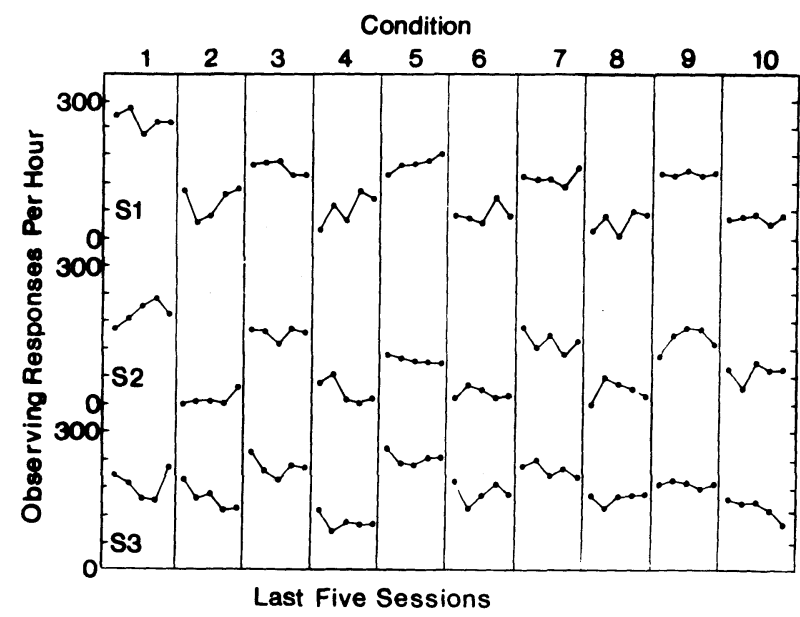

Figure 1. Number of observing responses per hour during the last five sessions of each of the 10 conditions. During odd-numbered conditions the center foodkey was the sole source of food reinforcement. During even-numbered conditions additional food reinforcement was presented. 
Table 2

Responses Per Minute on the Center Key in the Presence of Yellow (Y), Green (G), and Red (R) When Concurrent Reinforcement Was Present or Absent

\begin{tabular}{|c|c|c|c|c|c|c|c|c|c|}
\hline \multirow[b]{2}{*}{ Stimulus } & \multicolumn{3}{|c|}{ Subject $\mathrm{S} 1$} & \multicolumn{3}{|c|}{ Subject S2 } & \multicolumn{3}{|c|}{ Subject S3 } \\
\hline & $\mathrm{Y}$ & $\mathrm{G}$ & $\mathbf{R}$ & $\mathrm{Y}$ & G & $\mathbf{R}$ & $\mathbf{Y}$ & G & $\mathbf{R}$ \\
\hline \multicolumn{10}{|l|}{ Concurrent Reinforcement: } \\
\hline Present (Conditions $2,4,6,8,10$ ) & 5 & 55 & 0 & 15 & 56 & 0 & 12 & 69 & 0 \\
\hline Absent (Conditions $1,3,5,7,9$ ) & 14 & 53 & 0 & 31 & 59 & 0 & 32 & 69 & 0 \\
\hline
\end{tabular}

Since the concurrent reinforcement schedule occupied about $7 \%$ of total session time, one could expect a proportionate decrease in food and observing responding simply as a result of introducing the concurrent schedule. However, the decrements in both observing responding and center foodkey responding in the mixed stimulus were generally much larger than $7 \%$ and thus do not appear to be due to the simple presence of another schedule.

The decrement in observing that occurred when concurrent reinforcement was introduced shows that the inhibiting effects of concurrent reinforcement are not unique to behaviors maintained directly by food reinforcement. Observing responses are generally believed to be maintained indirectly by primary reinforcement-by the conditioned reinforcing value of multiple schedule stimuli that control differential response rates by virtue of their differential association with primary reinforcement availability (Wyckoff, 1969), or by the reinforcing value of information about primary reinforcement transmitted by multiple schedule stimuli (Hendry, 1969).

The decrease in center foodkey responding in the presence of the mixed schedule stimulus, but not in the presence of the multiple schedule stimulus associated with reinforcement, observed when concurrent reinforcement was introduced, suggests an inverse relationship between the inhibitory effects of concurrent reinforcement and the frequency of food reinforcement in the presence of a stimulus.

\section{REFERENCE NOTE}

1. Spencer, J. W. Observing behaviour in pigeons: An investigation of the reinforcing value of the negative discriminative stimulus. Unpublished Master's thesis, University of British Columbia, 1974.

\section{REFERENCES}

Catania, A. C. Concurrent performances: Reinforcement interaction and response independence. Journal of the Experimental Analysis of Behavior, 1963, 6, 253-263.

Catania. A. C. Concurrent operants. In W. K. Honig (Ed.), Operant behavior: Areas of research and application. New York: Appleton-Century-Crofts, 1966. Pp. 213-270.

Catania, A. C., \& Dobson, R. Concurrent performances: Rate and accuracy of free-operant oddity responding. Journal of the Experimental Analysis of Behavior, 1972, 17, 25-35.

HENDRY, D. P. Reinforcing value of information: Fixed-ratio schedules. In D. P. Hendry (Ed.), Conditioned reinforcement. Homewood. Illinois: Dorsey, 1969. Pp. 300-341.

WYCKOFF. L. B., JR. The role of observing responses in discrimination learning. In D. P. Hendry (Ed.), Conditioned reinforcement. Homewood, Illinois: Dorsey, 1969. Pp. 237-260.

(Received for publication December 17, 1975.) 